\title{
Effects of the Geopolitical Risks on Bitcoin Returns and Volatility
}

\author{
Ahmet Faruk Aysan, Ph.D. \\ Istanbul Sehir University, Istanbul, Turkey \\ E-mail: ahmetaysan@sehir.edu.tr \\ Ender Demir, Ph.D. \\ Istanbul Medeniyet University, Istanbul, Turkey \\ E-mail: ender.demir@medeniyet.edu.tr \\ Giray Gozgor, Ph.D. \\ Istanbul Medeniyet University, Istanbul, Turkey \\ E-mail: giray.gozgor@medeniyet.edu.tr \\ Chi Keung Marco Lau, Ph.D. \\ University of Huddersfield, Huddersfield, the United Kingdom \\ E-mail: c.lau@ hud.ac.uk
}

\begin{abstract}
This paper investigates the predictive power of global geopolitical risks (GPR) index on daily returns and price volatility of Bitcoin over the period July 18, 2010-November 30, 2017. Considering a Bayesian Graphical Structural Vector Autoregressive (BSGVAR) technique, we find that GPR has a predictive power on both returns and price volatility of Bitcoin. The results of the Ordinary Least Squares (OLS) estimations show that price volatility and returns of Bitcoin are positively and negatively related to the GPR, respectively. However, findings from the Quantile-on-Quantile (QQ) estimations state that effects are positive at the higher quantiles of both the GPR as well as price volatility and returns of Bitcoin. Therefore, we conclude that Bitcoin can be considered as a hedging tool against global geopolitical risks.
\end{abstract}

Keywords: Bitcoin; cryptocurrencies; geopolitical risks; BSGVAR model; Quantile-on-quantile estimations 


\section{$\underline{\text { Highlights }}$}

$>\quad$ We analyse predictive power of the GPR on returns and price volatility of Bitcoin

$>\quad$ The GPR has predictive power on returns and price volatility of Bitcoin

$>\quad$ Negative changes in the GPR significantly lead to greater Bitcoin returns

$>$ Effects of the GPR on both returns and volatility of Bitcoin are positive at the higher quantiles

$>\quad$ Bitcoin can be considered as a hedging tool against global geopolitical risks 


\section{Introduction}

Bitcoin has attracted the interest of governments, investors, and researchers since its introduction in 2008. But especially with its dramatic increases and decreases in 2017, the literature on Bitcoin and other cryptocurrencies has developed rapidly to better grasp the characteristics of those currencies. Although Bitcoin's dominance in the market has decreased from $90 \%$ in the early stages to around $40 \%$ recently, Bitcoin is still the most widely known cryptocurrency followed by Ethereum and Ripple.

An increasing number of study questions whether the Bitcoin market is efficient or is being more efficient in time. Cheah et al. (2018), Jiang et al. (2018), and Nadarajah and Chu (2017) show that Bitcoin markets are inefficient; while Kristoufek (2018) and Tiwari et al. (2018) also provide supporting evidence on the inefficiency of Bitcoin markets with exceptions of some periods. On the other hand side, Urquhart (2016) and Vidal-Tomás and Ibañez (2018) argue that Bitcoin has become more efficient over time. Using the Intraday data and the efficiency tests, Sensoy (2018) show that Bitcoin prices in terms of the EUR and the USD become more informationally efficient since 2016. Another strand of the literature documents the existence of speculative bubbles on Bitcoin (Cheah and Fry, 2015; Corbet et al. 2018a; Su et al. 2018). Urquhart (2018) examines the attention of drivers of Bitcoin. It is shown that both the realized volatility and the trading volume are the main factors affecting the next day attention (proxied by Google trends data) of Bitcoin. Dastgir et al. (2018) explore the causal relationship between Google Trends searches and Bitcoin returns and find a bi-directional causal relationship between them. The previous literature also shows that Bitcoin can provide diversification and hedging benefits for investors (Corbet al. 2018b; Dyhrberg, 2016a, 2016b; Guesmi et al. 2018;); however, Bouri et al. (2017a) find that Bitcoin has a poor hedge capacity, and it should be used for 
diversification purposes only. According to Ji et al. (2018), Bitcoin's diversification benefits decreases during the Bitcoin bear market periods.

In this study, we examine the impact of the geopolitical risks (GPR) index that is recently constructed by Caldara and Iacoviello (2018) to understand the effects of global tension, friction, and conflict on Bitcoin returns and volatility. The literature has shown a rising interest in terms of analysing the effects of the GPR index on financial markets and macroeconomic variables. Balcilar et al. (2018) examine the impact of the GPR on BRICS stock markets. They find that the GPRs do not affect the stock markets in a uniform way. While Russia is the most affected country India is found to be the least affected stock market. The GPR index impacts the stock market volatility rather than returns at return quantiles below the median. Likewise, Bouri et al. (2018a) also show that the GPR affect Islamic equity market volatility rather than returns. Cheng and Chiu (2018) show that the GPR has an important role in terms of explaining the business cycle fluctuations in emerging countries. Caldara and Iacoviello (2018) document that the GPRs lead to a decrease in real activity and stock returns and also drive capital flows from emerging economies to developed economies. Gkillas et al. (2018) show that the GPRs can predict volatility jumps in the Dow Jones Industrial Average and the GPRs also have negative effects on oil returns and volatility (Antonakakis et al., 2017)

As central bank officials, entrepreneurs, and market participants consider the GPRs as a key determinant of investment decisions and stock market dynamics (Caldara and Iacoviello, 2018), Bitcoin prices will be also affected from the GPR. The previous studies show that the GPR has a negative effect on stock returns implying that rising geopolitical risk makes investors sell their financial assets. This can lead to a capital flow from traditional financial markets to cryptocurrency markets. Therefore, increasing geopolitical risks is likely to positively affect the 
price of Bitcoin as investors can consider Bitcoin as a hedge against risk. Demir et al. (2018) consider the Economic Policy Uncertainty (EPU) index of Baker et al. (2016) as a determinant of Bitcoin prices. They show that EPU is able to successfully predict Bitcoin returns. Bouri et al. (2017b) measure uncertainty by using the volatility indices of 14 stock markets, and find that Bitcoin act as a hedge against uncertainty. Bouri et al. (2018c) use the global financial stress index as a risk proxy and examine its effect on Bitcoin. Financial stress causes Bitcoin returns at left and right tail of the latter's conditional distribution while this index has limited predictive power on Bitcoin. However, empirical evidence on Bitcoin's role as a safe haven against uncertainties is relatively scarce (Bouri et al. 2018c). Our paper contributes to this literature by examining the effects of GPR on Bitcoin. By using Bitcoin data from July 18, 2010, to November 30, 2017, we find that the changes in the global GPR index have a predictive power on price volatility and returns of Bitcoin. Using the OLS estimations, we show that there is a significant negative and a positive effect of the change in the GPR index on returns and the price volatility of Bitcoin, respectively. Nevertheless, the QQ regressions provided by Sim and Zhou (2015), we also document that the impact of the change in the global GPR index both on the price volatility and the returns of Bitcoin is positive and statistically significant at extreme cases. According to those findings, Bitcoin may be considered as the hedging instrument against global geopolitical risks, particularly during the extreme times of the global geopolitical risks.

The rest of the paper is organized as follows. Section 2 explains the data and the empirical model; while, Section 3 presents the findings. The last section concludes the paper with implications for investors. 


\section{Data and Model}

We use the logarithmic returns and price volatility of Bitcoin over the period July 18, 2010 to November 30, 2017. We have 2,693 observations, and the frequency of the data is daily. The beginning date of the analysis is based on the data availability of Bitcoin prices. Following Demir et al. (2018) and Katsiampa (2017), the Bitcoin price data is obtained from http://www.coindesk.com/price/. The price volatility of Bitcoin is calculated as the dynamic standard deviations of Bitcoin returns during the last five days.

We also consider the logarithmic change in the global GPR index that is constructed by Caldara and Iacoviello (2018). Caldara and Iacoviello (2018) define the geopolitical risk as the "risk associated with wars, terrorist acts, and tensions between states that affect the normal and peaceful course of international relations." ${ }^{11}$ Geopolitical risk is measured by the global GPR index and the GPR index reflects automated text-search results of the electronic archives of 11 international newspapers. Caldara and Iacoviello (2018) construct the GPR index by counting the number of articles related to geopolitical risk in each newspaper for each month (as a share of the total number of news articles), and it is then normalized to average a value of 100 for the period from 2000 to 2009. According to the data, the geopolitical risks have particularly increased during times of the 2014 Russia-Ukraine crisis and the Paris terrorist attacks in 2015. The GPR data is obtained from the webpage of Caldara and Iacoviello (2018). ${ }^{2}$ We develop the following empirical models:

$$
\Delta \ln (R B C)_{t}=\alpha_{1}+\beta_{1} \Delta \ln (G P R)_{t}+\varepsilon_{1 t}
$$

\footnotetext{
${ }^{1}$ Note that the GPR index considers not only the conflicts and political instability, but also the events of terrorism.

${ }^{2}$ For the details of the global GPR index, visit the webpage of Dario Caldara and Matteo Iacoviello, (https://www2.bc.edu/matteo-iacoviello/gpr.htm).
} 


$$
\Delta \ln (R B C)_{t}=\alpha_{2}+\beta_{2} \Delta \ln (G P R)_{t-k}+\varepsilon_{2 t}
$$

$$
\begin{aligned}
& V B C=\alpha_{3}+\beta_{3} \Delta \ln (G P R)_{t}+\varepsilon_{3 t} \\
& V B C=\alpha_{4}+\beta_{4} \Delta \ln (G P R)_{t-k}+\varepsilon_{4 t}
\end{aligned}
$$

From Eq. (1) to Eq. (4), $\Delta \ln (R B C)_{t}$ denotes the natural logarithmic returns of the Bitcoin prices at time t.VBC represents the price volatility of Bitcoin prices at time $t . \Delta \ln (G P R)_{t}$ and $\Delta \ln (G P R)_{t-k}$ provide the natural logarithmic change in the global GPR index at times $t$ and $\mathrm{t}-\mathrm{k}$, respectively. $\varepsilon_{t}$ represents the error term. Note that the correlation between the logarithmic returns of the Bitcoin price and the logarithmic change in the global GPR index is -0.011 . We also provide the econometric methodology in Appendix I. To provide the robustness of the main findings, we also consider the effects of various lagged coefficients of the GPR index on the returns and the price volatility of Bitcoin.

\section{Empirical Results and Discussion}

\subsection{Results of the BSGVAR Model Estimations}

Following Bouri et al. (2018b), the BSGVAR model is estimated via a three-year rolling window, and the three years (i.e. 1095 days) rolling window estimation over period July 19, 2013November 30, 2017. ${ }^{3}$ In Figure 1, the Bayesian Information Criteria (BIC) reports the values of the multivariate autoregressive (MAR) and the multivariate instantaneous (MIN) dependence structures and findings indicate that the former dependence structure (i.e. MAR) should be selected because of its smallest BIC over MIN (See Figure 1).

[Insert Figure 1 around here]

\footnotetext{
${ }^{3}$ Note that our data cover period July 18, 2010-November 30, 2017.
} 
Furthermore, the percentage of MAR structures as derived from the change in the geopolitical risks to Bitcoin returns of MAR links is shown in Figure 2. The highest interconnectedness between geopolitical risk index and Bitcoin returns is evident during the period from April 15, 2016, to June 3, 2017. Following these results, we find the significant "lead-lag relationship" for the structural breaks for global GPR measure and the total linkage values of Bitcoin returns.

[Insert Figure 2 around here]

Looking at the price volatility of Bitcoin, BSGVAR model is estimated via a three-year rolling window, and the three years (i.e. 1095 days) rolling window estimation over period July 19, 2013-November 30, 2017. In Figure 3, BIC reports the values of MAR and MIN dependence structures, and results state that MAR structure should be selected since it provides the smallest BIC over MIN (See Figure 3).

[Insert Figure 3 around here]

Furthermore, percentage of MAR structures as derived from the change in geopolitical risk measure to the price volatility of Bitcoin of MAR links is reported in Figure 4. The highest interconnectedness between the geopolitical risk index and the price volatility of Bitcoin is evident for the period from the beginning of 2017. In the light of these findings, we observe the "lead-lag relationship" for the structural breaks of global GPR index and total linkage values of the price volatility of Bitcoin. In short, we observe that GPR is able to successfully predict on returns and price volatility of Bitcoin.

[Insert Figure 4 around here] 


\subsection{Findings from $O L S$ and $Q Q$ Regressions}

To obtain the magnitude of the impact of the GPR measure on Bitcoin returns, we report the findings of OLS and QQ regressions in Table 1.

[Insert Table 1 around here]

The findings from OLS regressions indicate that the impact of GPR index on the returns of Bitcoin is negative and statistically significant at the 5\% level. The lagged coefficients of the GPR index (from lag 1 to lag 24) provide the negative relationship, but their coefficients are not statistically significant. In addition, we provide the QQ estimations at the different quantiles. It is interesting to observe that the effects of the GPR index on the returns of Bitcoin are mostly statistically significant when we consider the GPR and GPR (-1). Looking at the GPR (-12) and GPR (-24), there is no statistically significant relationship, while the GPR (-4) and GPR (-8) provide the positive effects of the GPR index on the returns of Bitcoin at the different quantiles. The findings from the GPR (-2) indicate that the relationship is negative at the central quantiles, but the findings are only significant at the $10 \%$ level. It is noteworthy to indicate that the effects of the GPR and GPR (-1) are negative in both the lower and the central quantiles, and most of the coefficients are statistically significant. However, this relationship changes to positive direction (still statistically significant) when we consider upper quantiles, such as $0.85,0.90$, and 0.95. It is also interesting to find that the effects of the GPR, GPR $(-1)$, GPR $(-2)$, GPR $(-4)$, GPR (-8), GPR (-12), and GPR (-24) are positive at the upper quantiles $(0.80,0.85,0.90$, and 0.95), but the relationship is statistically significant only for the coefficients of the GPR and GPR $(-1)$. This finding provides that the predictive power of the extreme events of the GPR index on the extreme positive returns of Bitcoin only exists in the short term, i.e. mostly one transaction day. 
Fundamentally, our findings illustrate that an increase in the GPR index will reduce the returns of Bitcoin. However, the impact of the GPR index on the returns of Bitcoin changes to a positive direction when we look at upper quantiles. This evidence implies that Bitcoin should be used as the hedging instrument against geopolitical risks during times of bull Bitcoin market (i.e. high returns in the market). At this point, investors on Bitcoin market can consider our findings and they should watch global geopolitical risks when they manage portfolios on the cryptocurrencies. Another implication of our findings is that investors on Bitcoin market can predict the returns of Bitcoin via the development of the related geopolitical risk index.

In addition, to obtain the magnitude of the effects of the GPR indexes on the price volatility of Bitcoin, we report the findings of OLS and QQ regressions in Table 2.

[Insert Table 2 around here]

The results of the OLS estimations in Table 2 show that the impact of the GPR index on the price volatility of Bitcoin is positive, but it is statistically insignificant. Besides, the lagged coefficients of the GPR index (from lag 1 to lag 24) illustrate the positive relationship, but the coefficients are also statistically insignificant. Additionally, we report the QQ estimations at the different quantiles. It is interesting to find that the effects of the GPR index on the price volatility of Bitcoin are only statistically significant when we focus on the GPR and GPR (-1). Looking at the GPR (-2), GPR (-4), GPR (-8), GPR $(-12)$, and GPR (-24), there is no statistically significant relationship, and the results mostly provide the positive effects of the GPR on the price volatility of Bitcoin return at the different quantiles.

It is also noteworthy to indicate that the effects of the GPR and GPR (-1) are positive in both the lower and the central quantiles, but the coefficients are statistically insignificant. However, the relationship turns to be statistically significant (and positive) when we consider the 
upper quantiles, such as $0.85,0.90$, and 0.95 . It is also interesting to find that the effects of the GPR, GPR (-1), GPR (-2), GPR (-4), GPR (-8), GPR (-12), and GPR (-24) are positive at the upper quantiles $(0.80,0.85,0.90$, and 0.95$)$, but the relationship is only statistically significant for the coefficients of the GPR and GPR (-1). These results imply that there is the predictive power of the extreme events of the GPR on the extreme price volatility of Bitcoin, but it only exists in the very short term, i.e. the price volatility of a current day.

These results imply several implications. For instance, Bitcoin should be seen as a significant tool to hedge the portfolio against geopolitical risks. Our findings are in line with the papers of Bouri et al. (2017b) and Demir et al. (2018), which illustrate that the effects of risk and uncertainty indicators on Bitcoin return are negative in the baseline findings; however, Bitcoin should be considered for hedging against geopolitical risks in the bull-market conditions. However, Bitcoin should be included in portfolios to provide the portfolio diversification in the bear-market conditions. We also enhance the previous findings to observe the positive impact of geopolitical risks the price volatility of Bitcoin at the higher quantiles.

It is also important to indicate that the future path of the geopolitical risk index can help to predict the returns and the price volatility of Bitcoin since it is observed as the vulnerability of Bitcoin market. Because of the cryptocurrencies are still in the development process, the policymakers in developed countries and developing economies should aware that the risks due to the conflicts, political instability, and terrorism can significantly affect the price volatility and the returns of Bitcoin. In terms of investors, market participants of the cryptocurrencies should monitor not only the naturally existing risks of cryptocurrencies but also the geopolitical risk in order to hedge their portfolios against potential risks. 


\section{Conclusion}

We analysed the predictive power of the global GPR index on daily returns and price volatility of Bitcoin over period July 18, 2010-November 30, 2017. Implementing BGSVAR estimation procedure, we find that the changes in the global GPR index have a predictive power on price volatility and returns of Bitcoin. Using the OLS estimations, we show that there is a significant negative and a positive effect of the change in the GPR index on returns and price volatility of Bitcoin, respectively. Nevertheless, using the QQ estimation techniques, we document that the impact of change in global GPR index on price volatility and returns of Bitcoin are positive and statistically significant at upper quantiles. According to those findings, Bitcoin should be considered as a hedging tool against global geopolitical risks, particularly during the extreme times of the global geopolitical risks.

Future studies can focus on other risk and uncertainty indicators to investigate their effects on cryptocurrencies. For example, researchers can use the domestic political risk indicators in the large economies, such as China, India, Russia, and the United States. Researchers can use the high frequency data (intraday data) to provide the effects of risk and uncertainty indicators on the price of Bitcoin. At this point, we should enhance our academic knowledge of the drivers of the returns of the cryptocurrencies and the determinants of price volatility in the cryptocurrency markets.

\section{References}

Ahelegbey, D.F., Billio, M., \& Casarin, R. (2016). Bayesian graphical models for structural vector autoregressive processes. Journal of Applied Econometrics, 31 (2), 357-386. 
Antonakakis, N., Gupta, R., Kollias, C., \& Papadamou, S. (2017). Geopolitical risks and the oilstock nexus over 1899-2016. Finance Research Letters, 23, 165-173.

Baker, S.R., Bloom, N., \& Davis, S.J. (2016). Measuring economic policy uncertainty. The Quarterly Journal of Economics, 131 (4), 1593-1636.

Balcilar, M., Bonato, M., Demirer, R., \& Gupta, R. (2018). Geopolitical risks and stock market dynamics of the BRICS. Economic Systems, forthcoming.

Bouri, E., Demirer, R., Gupta, R., \& Marfatia, H. A. (2018a). Geopolitical risks and movements in Islamic bond and equity markets: A note. Defence and Peace Economics, forthcoming.

Bouri, E., Gupta, R., Hosseini, S., \& Lau, C.K.M. (2018b). Does global fear predict fear in BRICS stock markets? Evidence from a Bayesian Graphical Structural VAR model. Emerging Markets Review, 34, 124-142.

Bouri, E., Gupta, R., Lau, C.K.M., Roubaud, D., \& Wang, S. (2018c). Bitcoin and global financial stress: A Copula-based approach to dependence and causality-in-quantiles. The Quarterly Review of Economics and Finance, forthcoming.

Bouri, E., Gupta, R., Tiwari, A. K., \& Roubaud, D. (2017b). Does Bitcoin hedge global uncertainty? Evidence from wavelet-based quantile-in-quantile regressions. Finance Research Letters, 23, 87-95.

Bouri, E., Molnár, P., Azzi, G., Roubaud, D., \& Hagfors, L. I. (2017a). On the hedge and safe haven properties of Bitcoin: Is it really more than a diversifier? Finance Research Letters, 20, 192-198.

Caldara, D., \& Iacoviello, M. (2018). Measuring geopolitical risk. Board of Governors of the Federal Reserve Board Working Paper, Version: January 10, 2018. 
Cheah, E.T., \& Fry, J. (2015). Speculative bubbles in Bitcoin markets? An empirical investigation into the fundamental value of Bitcoin. Economics Letters, 130, 32-36.

Cheah, E.T., Mishra, T., Parhi, M., \& Zhang, Z. (2018). Long memory interdependency and inefficiency in Bitcoin markets. Economics Letters, 167, 18-25.

Cheng, C.H.J., \& Chiu, C-W.J. (2018). How important are global geopolitical risks to emerging countries? International Economics, forthcoming.

Corbet, S., Lucey, B., \& Yarovya, L. (2018a). Datestamping the Bitcoin and Ethereum bubbles. Finance Research Letters, forthcoming.

Corbet, S., Meegan, A., Larkin, C., Lucey, B., \& Yarovaya, L. (2018b). Exploring the dynamic relationships between cryptocurrencies and other financial assets. Economics Letters, 165, $28-34$.

Dastgir, S., Demir, E., Downing, G., Gozgor, G., \& Lau, C. K. M. (2018). The causal relationship between Bitcoin attention and Bitcoin returns: Evidence from the Copulabased Granger causality test. Finance Research Letters, forthcoming.

Demir, E., Gozgor, G., Lau, C.K.M., \& Vigne, S.A. (2018). Does economic policy uncertainty predict the Bitcoin returns? An empirical investigation. Finance Research Letters, forthcoming.

Dyhrberg, A.H. (2016a). Hedging capabilities of bitcoin. Is it the virtual gold? Finance Research Letters, 16, 139-144.

Dyhrberg, A.H. (2016b). Bitcoin, gold and the dollar - A GARCH volatility analysis. Finance Research Letters, 16, 85-92

Gkillas, K., Gupta, R., \& Wohar, M.E. (2018). Volatility jumps: The role of geopolitical risks. Finance Research Letters, forthcoming. 
Guesmi, K., Saadi, S., Abid, I., \& Ftiti, Z. (2018). Portfolio diversification with virtual currency: Evidence from bitcoin. International Review of Financial Analysis, forthcoming.

Ji, Q., Bouri, E., Gupta, R., \& Roubaud, D. (2018). Network causality structures among Bitcoin and other financial assets: A directed acyclic graph approach. The Quarterly Review of Economics and Finance, forthcoming.

Jiang, Y., Nie, H., \& Ruan, W. (2018). Time-varying long-term memory in Bitcoin market. Finance Research Letters, 25, 280-284.

Katsiampa, P. (2017). Volatility estimation for Bitcoin: A comparison of GARCH models. Economics Letters, 158, 3-6.

Kristoufek, L. (2018). On Bitcoin markets (in) efficiency and its evolution. Physica A: Statistical Mechanics and its Applications, 503, 257-262.

Nadarajah, S., \& Chu, J. (2017). On the inefficiency of Bitcoin. Economics Letters, 150, 6-9.

Sensoy, A. (2018). The inefficiency of Bitcoin revisited: A high-frequency analysis with alternative currencies. Finance Research Letters, forthcoming.

Sim, N., \& Zhou, A. (2015). Oil prices, US stock return, and the dependence between their quantiles. Journal of Banking and Finance, 55, 1-8.

Su, C.W., Li, Z.Z., Tao, R., \& Si, D.K. (2018). Testing for multiple bubbles in bitcoin markets: A generalized sup ADF test. Japan and the World Economy, 46, 56-63.

Tiwari, A.K., Jana, R.K., Das, D., \& Roubaud, D. (2018). Informational efficiency of Bitcoinan extension. Economics Letters, 163, 106-109.

Urquhart, A. (2018). What causes the attention of Bitcoin? Economics Letters, 166, 40-44.

Urquhart, A. (2016). The inefficiency of Bitcoin. Economics Letters, 148, 80-82. 
Vidal-Tomás, D., \& Ibañez, A. (2018). Semi-strong efficiency of Bitcoin. Finance Research Letters, forthcoming.

Figure 1.

Bayesian Information Criteria of Contemporaneous and Temporal Dependence Structures (Returns of Bitcoin)

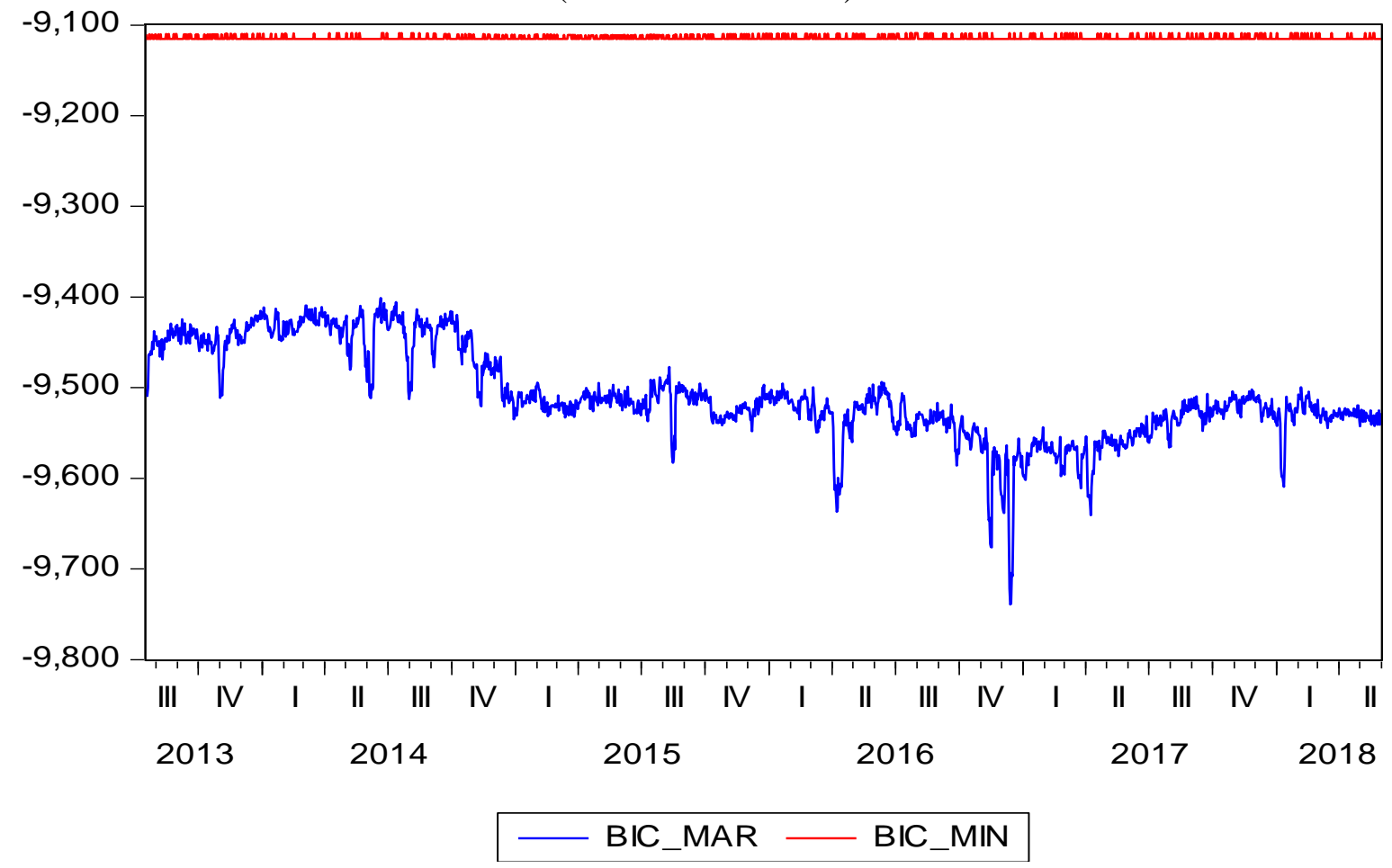

Figure 2.

Multivariate Autoregressive Model and the Lead-Lag Linkage (Returns of Bitcoin) 


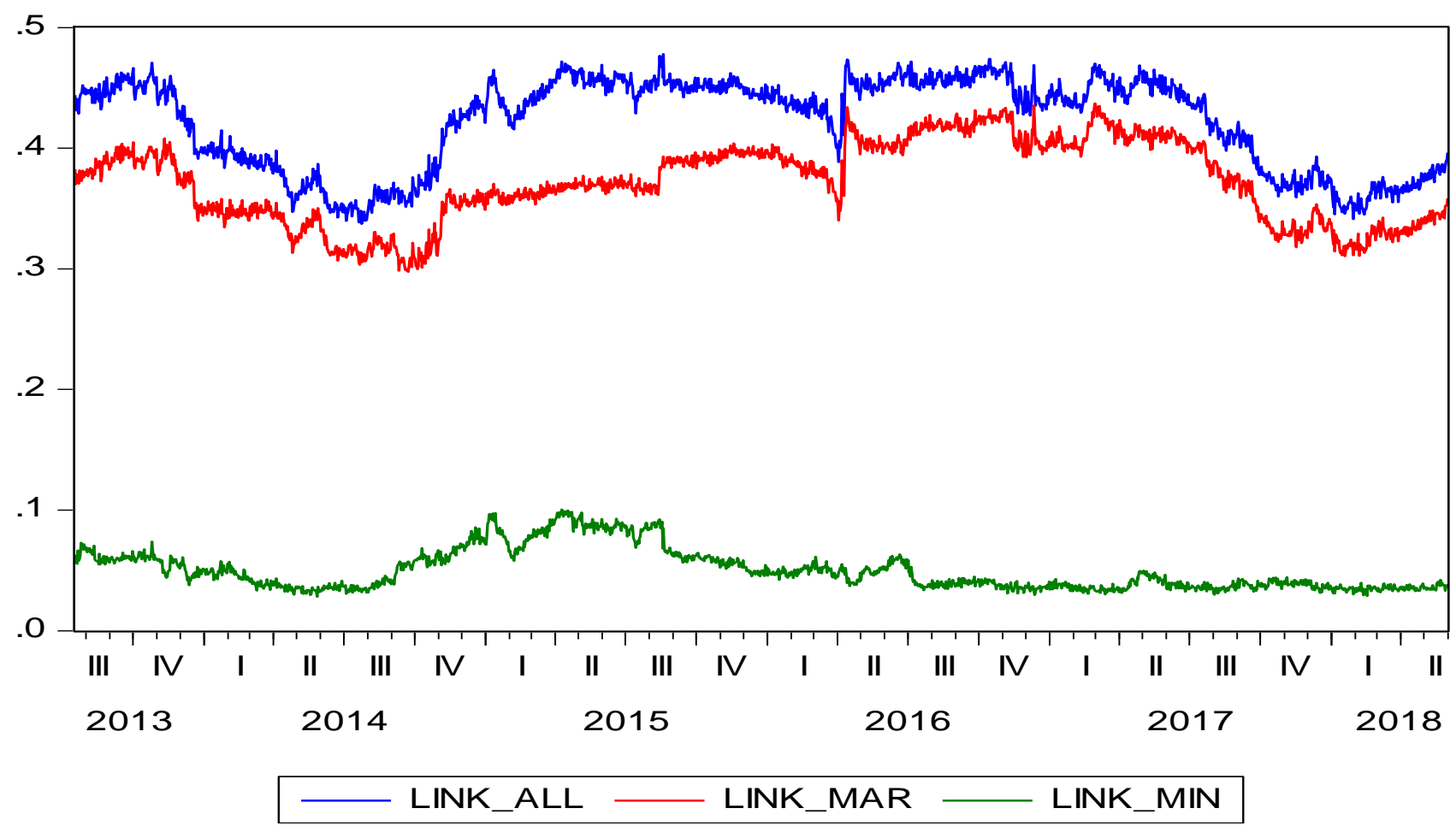

Figure 3.

Bayesian Information Criteria of Contemporaneous and Temporal Dependence Structures (Price Volatility of Bitcoin)

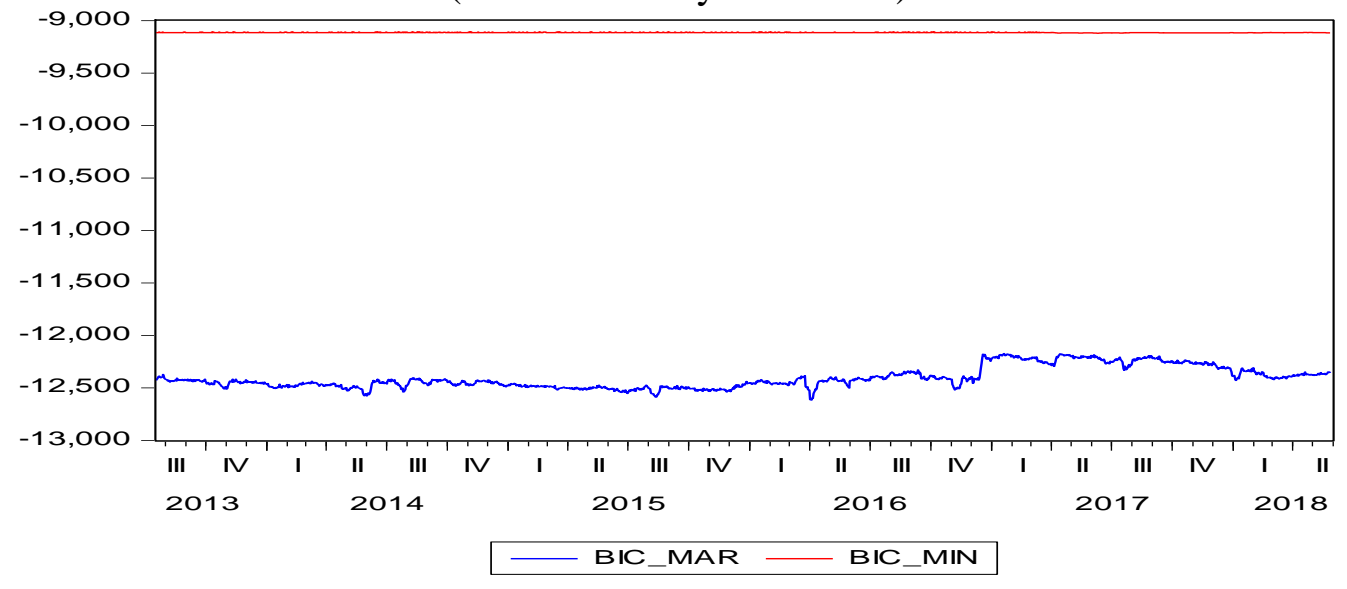

Figure 4.

Multivariate Autoregressive Model and the Lead-Lag Linkage (Price Volatility of Bitcoin) 


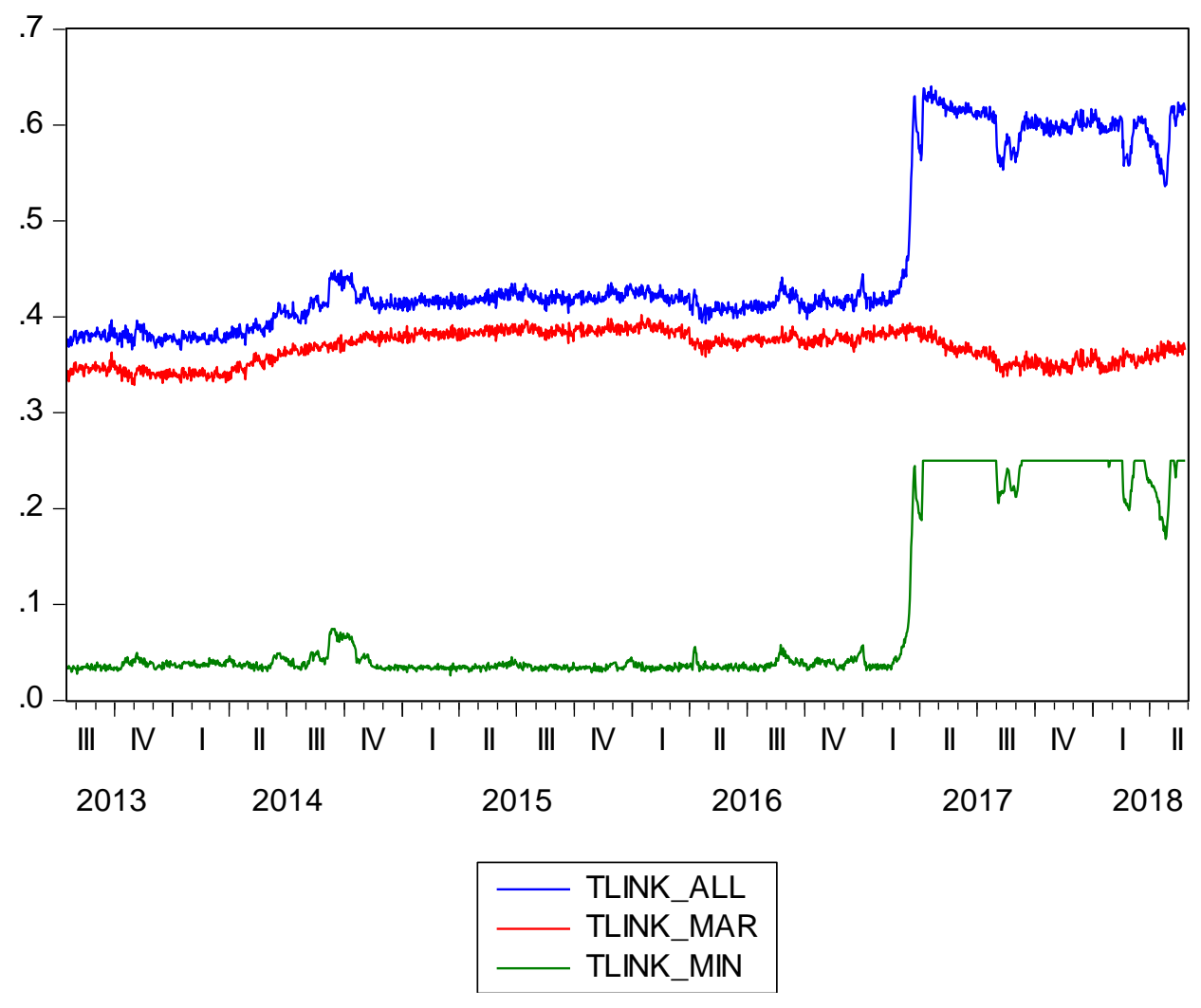

Table 1.

Results of the OLS and the QQ Estimations: Returns of Bitcoin

\begin{tabular}{c|ccccccc}
\hline Estimation Techniques & $\Delta \mathrm{GPR}$ & $\Delta \mathrm{GPR}(-1)$ & $\Delta \mathrm{GPR}(-2)$ & $\Delta \mathrm{GPR}(-4)$ & $\Delta \mathrm{GPR}(-8)$ & $\Delta \mathrm{GPR}(-12)$ & $\Delta \mathrm{GPR}(-24)$ \\
\hline OLS & $-0.01^{* *}$ & -0.21 & -0.04 & 0.12 & 0.22 & -0.16 & -0.05 \\
\hline QQ at the Different Quantiles & $\Delta \mathrm{GPR}$ & $\Delta \mathrm{GPR}(-1)$ & $\Delta \mathrm{GPR}(-2)$ & $\Delta \mathrm{GPR}(-4)$ & $\Delta \mathrm{GPR}(-8)$ & $\Delta \mathrm{GPR}(-12)$ & $\Delta \mathrm{GPR}(-24)$ \\
\hline 0.05 & -0.64 & -0.86 & -0.08 & 0.30 & 0.18 & -0.10 & -0.63 \\
0.10 & -0.56 & $-0.54^{*}$ & -0.09 & 0.05 & 0.31 & -0.44 & -0.02 \\
0.15 & $-0.39^{*}$ & $-0.52^{* *}$ & -0.07 & 0.05 & 0.34 & -0.30 & -0.14 \\
0.20 & -0.19 & $-0.43^{* * *}$ & -0.19 & 0.02 & $0.31^{* *}$ & -0.22 & 0.04 \\
0.25 & -0.17 & $-0.27^{* * *}$ & -0.20 & 0.01 & 0.14 & -0.01 & -0.09 \\
0.30 & $-0.15^{*}$ & $-0.28^{* * *}$ & -0.12 & 0.04 & 0.09 & -0.05 & -0.13 \\
0.35 & $-0.12^{*}$ & $-0.23^{* * *}$ & -0.11 & 0.09 & $0.15^{* *}$ & -0.03 & -0.14 \\
0.40 & $-0.10^{*}$ & $-0.14^{* *}$ & $-0.10^{*}$ & 0.04 & 0.09 & -0.02 & -0.08 \\
0.45 & $-0.07^{* *}$ & -0.04 & -0.02 & 0.04 & 0.03 & -0.05 & -0.17 \\
0.50 & -0.07 & $-0.14^{* *}$ & -0.09 & 0.08 & 0.09 & -0.01 & -0.10 \\
0.55 & -0.06 & $-0.18^{* * *}$ & $-0.11^{*}$ & $0.05^{*}$ & $0.17 * *$ & 0.03 & -0.06 \\
0.60 & -0.02 & $-0.18^{* *}$ & -0.11 & $0.05^{* *}$ & $0.19 * *$ & 0.09 & -0.06 \\
0.65 & -0.04 & $-0.19^{*}$ & -0.09 & $0.15^{*}$ & $0.16^{*}$ & 0.06 & 0.01 \\
0.70 & -0.16 & $-0.31^{* *}$ & -0.08 & 0.32 & 0.21 & 0.13 & 0.08
\end{tabular}




\begin{tabular}{l|cccccccc}
0.75 & 0.12 & $-0.35^{* *}$ & 0.04 & 0.39 & 0.28 & 0.10 & 0.11 \\
0.80 & 0.09 & $0.30^{*}$ & 0.13 & 0.35 & 0.33 & 0.07 & 0.02 \\
0.85 & $0.08^{*}$ & $0.26^{*}$ & 0.24 & 0.19 & $0.41^{* *}$ & 0.08 & 0.04 \\
0.90 & $0.06^{* * *}$ & $0.36^{* *}$ & 0.35 & 0.13 & $0.34^{*}$ & 0.11 & 0.10 \\
0.95 & $0.32 * *$ & $0.10^{*}$ & 0.03 & 0.19 & $0.94 * *$ & 0.57 & 0.56 \\
\hline
\end{tabular}

Notes: $* p<0.10$, ** $p<0.05$, *** $p<0.01$. We use the robust standard errors.

Table 2.

Results of the OLS and the QQ Estimations: Price Volatility of Bitcoin

\begin{tabular}{c|ccccccc}
\hline Estimation Techniques & $\Delta \mathrm{GPR}$ & $\Delta \mathrm{GPR}(-1)$ & $\Delta \mathrm{GPR}(-2)$ & $\Delta \mathrm{GPR}(-4)$ & $\Delta \mathrm{GPR}(-8)$ & $\Delta \mathrm{GPR}(-12)$ & $\Delta \mathrm{GPR}(-24)$ \\
\hline OLS & 0.10 & 0.52 & 0.03 & 0.22 & 0.14 & 0.36 & 0.11 \\
\hline QQ at the Different Quantiles & $\Delta \mathrm{GPR}$ & $\Delta \mathrm{GPR}(-1)$ & $\Delta \mathrm{GPR}(-2)$ & $\Delta \mathrm{GPR}(-4)$ & $\Delta \mathrm{GPR}(-8)$ & $\Delta \mathrm{GPR}(-12)$ & $\Delta \mathrm{GPR}(-24)$ \\
\hline 0.05 & 0.24 & 0.03 & 0.13 & 0.03 & 0.01 & 0.22 & -0.25 \\
0.10 & 0.23 & -0.03 & 0.10 & -0.02 & 0.02 & 0.03 & 0.28 \\
0.15 & 0.04 & 0.01 & 0.04 & 0.08 & 0.12 & -0.21 & 0.21 \\
0.20 & 0.03 & 0.01 & -0.17 & 0.06 & 0.01 & 0.22 & 0.13 \\
0.25 & 0.05 & 0.03 & 0.10 & 0.04 & -0.02 & 0.06 & 0.23 \\
0.30 & 0.23 & 0.02 & 0.02 & 0.05 & 0.05 & 0.10 & 0.17 \\
0.35 & 0.27 & 0.06 & 0.02 & 0.07 & 0.08 & 0.07 & 0.22 \\
0.40 & -0.11 & 0.07 & 0.10 & -0.12 & 0.09 & 0.03 & 0.04 \\
0.45 & 0.08 & 0.17 & -0.13 & 0.08 & 0.16 & 0.01 & 0.01 \\
0.50 & 0.05 & 0.02 & 0.04 & 0.12 & 0.05 & 0.04 & 0.02 \\
0.55 & 0.12 & 0.04 & 0.11 & 0.09 & 0.04 & 0.05 & -0.07 \\
0.60 & 0.04 & 0.04 & 0.06 & 0.12 & 0.03 & 0.04 & 0.07 \\
0.65 & 0.05 & 0.02 & 0.09 & 0.07 & -0.05 & 0.07 & 0.08 \\
0.70 & 0.33 & 0.03 & -0.04 & 0.03 & 0.08 & -0.06 & 0.05
\end{tabular}




\begin{tabular}{l|ccccccc}
0.75 & 0.03 & 0.07 & 0.05 & -0.13 & 0.01 & 0.03 & 0.05 \\
0.80 & 0.02 & 0.07 & 0.12 & 0.02 & 0.04 & 0.08 & 0.12 \\
0.85 & $0.26^{*}$ & 0.03 & 0.27 & 0.03 & 0.07 & 0.20 & 0.08 \\
0.90 & $0.27 * *$ & $0.02 *$ & 0.20 & 0.11 & 0.06 & 0.04 & 0.23 \\
0.95 & $0.26 * * *$ & 0.09 & 0.25 & 0.11 & 0.24 & 0.33 & 0.35 \\
\hline
\end{tabular}

\section{Appendix I. Econometric Methodology}

The contemporaneous and the delayed causality between the response variable (i.e. $\mathrm{Y}_{\mathrm{t}}$ ) and the predictor variable (i.e. $\mathrm{X}_{\mathrm{t}}$ ) is estimated by the Bayesian Graphical Structural Vector Autoregressive (BGSVAR) model. The dependence/causality dynamic can be written as follows:

$Y_{t}=B_{0} Y_{t}+\sum_{i=1}^{p} B_{i} Y_{t-i}+\sum_{i=1}^{p} C_{i} Z_{t-i}+\varepsilon_{t}$

Where $t=1, \ldots, T$ and $p$ is the maximum lag order. $Y_{t}$ and $Z_{t}$ are the vector of the returns of Bitcoin and the change in the global geopolitical risk (GPR) index. The reduced form of Eq. (A1) can be written as follows:

$Y_{t}=A_{1} X_{t-1}+\ldots A_{p} X_{t-p}+u_{t}$

where $X_{t}=\left(Y_{t}, Z_{t}\right)^{\prime}=\left(X_{1 t}, X_{2 t}, \ldots, X_{n t}\right)^{\prime}$ is an $n=n_{y}+n_{z}$ dimensional time series; $B_{i}^{*}=$ $\left(B_{i}, C_{i}\right), 1 \leq i \leq p$, are $\left(n_{y} \times n\right)$ matrices of the unknown coefficients; $A_{0}=\left(I_{n_{y}}-B_{0}\right)$ is a $\left(n_{y} \times n_{y}\right)$ matrix; $A_{i}=A_{0}^{-1} B_{i}^{*}, 1 \leq i \leq p$, are $\left(n_{y} \times n\right)$ the reduced-form lag coefficient matrices; and $u_{t}=A_{0}^{-1} \varepsilon_{t}$ is an $\left(n_{y} \times 1\right)$ independently and identically distributed (iid.) reducedform vector residual term with a zero mean and a covariance matrix $\Sigma_{u}$. 
Specifically, we aim to investigate the dynamic relationship between returns of Bitcoin and the index of geopolitical risks as well as the dynamic relationship between price volatility of Bitcoin and the index of geopolitical risks. For this purpose, we use the BGSVAR model of Ahelegbey et al. (2016) to tackle the issues of the misidentification of the system equations and the assumption of the implausible restrictions (Bouri et al. 2018b). There are two simple representations of the Contemporaneous Network $(\mathrm{CN})$ and the Lagged Network (LN) causality structures are adopted within the BGSVAR framework. For more details about those estimation and inference techniques, refer to Ahelegbey et al. (2016).

Furthermore, using the Markov Chain Monte Carlo (MCMC) process and the small-size network methods, we estimate the LN component and the CN component. The MIN and the MAR structures respectively, provide the posterior probabilities for the instantaneous and the lagged relationships between the returns of Bitcoin and the GPR index as well as the price volatility of Bitcoin and the GPR index. It is noteworthy to note that Bouri et al. (2018b) use the BSGVAR model to predict the returns of stock markets in BRICS economies using the volatility index (VIX) index as a predictor. Similarly, Demir et al. (2018) consider the BSGVAR model to predict the returns in Bitcoin using the economic policy uncertainty (EPU) index. In this paper, we use an alternative proxy for uncertainty measure, i.e. the geopolitical risks (GPR), as a potential predictor of the Bitcoin returns and the price volatility of Bitcoin.

Finally, we consider the Ordinary Least Squares (OLS) and the Quantile-on-quantile Regression (QQ) estimations to examine the quantile of returns and price volatility of Bitcoin at various frequencies from 0.05 to 0.95 as the function of the quantile of the global GPR index that provides each significant point of their distributions. In here, we follow the QQ estimation technique of Sim and Zhou (2015). For the details of the QQ estimation technique, refer to Sim and Zhou (2015). 